\title{
Do we need new asthma control tests?
}

\author{
Jean Bousquet ${ }^{1,2}$, Arnaud Bourdin ${ }^{1,3}$ and Pascal Demoly ${ }^{4}$ \\ Affiliations: 'Dept of Respiratory Diseases, University Hospital, Hôpital Arnaud de Villeneuve, Montpellier, \\ France. ${ }^{2}$ Inserm, CESP Centre for Research in Epidemiology and Population Health, U1018, Respiratory and \\ Environmental Epidemiology Team, Villejuif, France. ${ }^{3}$ Inserm U1046, Montpellier University 1 and 2, \\ Montpellier, France. ${ }^{4}$ Allergy Division, Dept of Pneumology, Inserm U657, Hôpital Arnaud de Villeneuve, \\ University Hospital of Montpellier, Montpellier, France.
}

Correspondence: Jean Bousquet, Hôpital Arnaud de Villeneuve, Dept Pneumologie-Addictologie, 34295 Montpellier Cx 5, France. E-mail: jean.bousquetdorange.fr

0 @ERSpublications

Do we need new asthma control tests? The new RAND-ACM and its potential for the future http://ow.ly/B7JHK

The assessment of asthma control is pivotal to the evaluation of treatment response. The National Asthma Education and Prevention Program (NAEPP) guidelines and the 2006 update of the Global Initiative for Asthma (GINA) proposed to use asthma control (control of manifestations of the disease) to guide treatment [1]. It is important in clinical practice to identify patients with uncontrolled asthma, since they have a risk of exacerbations [2]. Asthma control may be assessed using several approaches [3,4]. There is no gold standard for the assessment of asthma control, which is usually considered to be a continuum from total to poor control [3-5]. The concept of composite measures for the assessment of asthma control is based on 1) the generally poor correlation between different domains of asthma, 2) the lack of a single gold standard and 3) the use of multiple end-points providing a more complete picture of asthma control than a single end-point $[3,4]$. The GINA guidelines propose a questionnaire for recent events and exacerbations over the past year [1]. Results of pulmonary function tests are added to the definition. However, albeit recommended, pulmonary function tests are unavailable in most practices throughout the world. The asthma control questionnaires (e.g. the Asthma Control Questionnaire (ACQ) and Asthma Control Test (ACT) ) are based on a series of questions and can only be applied at regular intervals of 1-4 weeks. Furthermore, most do not use pulmonary function tests [6]. In the ACQ, inclusion of the level of pulmonary function does not improve the assessment of asthma control [7].

The RAND Corporation is a nonprofit institution that helps improve policy and decision making through research and analysis. For more than 60 years, RAND research has not been limited to healthcare. RAND is highly respected for operating independently of political and commercial pressures. RAND research is commissioned by a global clientele that includes government agencies, foundations and private-sector firms. RAND had previously developed an eight-item asthma symptom scale for adults [8]. RAND attempted to refine this self-administered asthma symptom scale in order to shorten it, to validate it and to reflect international definitions of asthma control, producing the RAND Asthma Control Measure (RAND-ACM). LARA et al. [9] studied a sample of 2032 adults with asthma using the rigorous psychometric testing of RAND-ACM, which does not include measures of the pulmonary function. The reliability and validity of the RAND-ACM were at least similar to that of the original RAND measure and the ACT [10]. RAND-ACM scores were significantly associated with asthma-related quality of life and asthma-related healthcare use. Strong evidence for internal consistency was observed. LARA et al. [9] also found adequate concordance between the RAND-ACM and the GINA categories of "uncontrolled", "partly controlled" and "controlled" asthma. The RAND-ACM was found to perform well in a large ethnically diverse sample of adults in the USA with asthma and a degree of education [9]. However, the data were obtained from a relatively welleducated adult sample. One of the major advantages of the RAND-ACM is that it is a cost-free alternative to

Received: Sept 032014 | Accepted: Sept 032014

Conflict of interest: Disclosures can be found alongside the online version of this article at erj.ersjournals.com

Copyright @ERS 2014 
other asthma control measures currently available and may therefore become the standard asthma control test. However, as pointed out by the authors, the RAND-ACM has not been tested in longitudinal surveys, and the test-retest reliability as well as the responsiveness to treatment have not yet been established. Moreover, it has not been translated, adapted to the culture of different countries or validated for use outside the USA. Until this is achieved, the RAND-ACM can be used in patients in the USA only.

Thus, although this new asthma control test appears to be similar or superior to previous ones, and its major advantage is that of being a cost-free alternative, do we really need new asthma control tests? The question is of importance, since the implementation of self-management programmes in clinical practice using control tests, and their uptake by patients, is still insufficient. Recent mobile technology development (e.g. smartphone and tablet computer applications) may help to better control asthma by self-management interventions that are customisable, of low-cost and easily accessible. The current evidence is not sufficient to advise clinicians, policy-makers and the general public to use smartphone and tablet computer applications for the delivery of asthma self-management programmes [11]. However, studies have not evaluated these mobile technology developments as part of complex, multicomponent interventions. Researchers should take into account the role of ancillary components in moderating the observed effects, the seasonal nature of asthma and the long-term adherence to self-management practices [11]. For these new technologies, easily measured daily control tests should be used.

The visual analogue scale (VAS) measures subjective phenomena [12]. It provides a continuous scale for subjective magnitude estimation, takes relatively little time to complete and allows cross-cultural comparisons due to minimal language translation difficulties. The VAS has been widely used for the assessment of subjective symptoms such as pain. It appears that changes in VAS levels are more accurate than single assessments, but the same is probably true for all control tests. In allergic rhinitis, VAS levels correlate with the severity of the disease [13] and changes during treatment [14]. Moreover, this could be applied daily. In asthma, very few studies have used VAS [15-17], but this instrument has compared favourably with asthma control assessed by GINA in a very large patient population in Japan [18]. Pilot studies using VAS and mobile phone technologies should be initiated in order to determine their costeffectiveness. Given the enthusiasm with mHealth (mobile health, a term used for the practice of medicine and public health supported by mobile devices), interventions are currently being implemented, and further research into these issues is needed [19]. VAS is a very simple tool validated in a large number of languages and, while mHealth has been used in developed countries, the field has emerged in recent years largely as an application for developing countries, stemming from the rapid rise of mobile phone penetration in lowincome countries. Thus, this new form of asthma control test may prove to be global and serve patients in all countries and all settings: mHealth is a means of providing greater access to larger segments of a population in developing countries, as well as improving the capacity of health systems in such countries to provide quality healthcare.

The future of asthma control tests is probably that of mixing old technology with newer technologies. Simplicity of asthma control questionnaires will be required and, possibly, a unique VAS might be relevant to assess the daily control of asthma. These are questions which need to be answered.

\section{References}

1 Bateman ED, Hurd SS, Barnes PJ, et al. Global strategy for asthma management and prevention: GINA executive summary. Eur Respir J 2008; 31: 143-178.

2 Bateman ED, Reddel HK, Eriksson G, et al. Overall asthma control: the relationship between current control and future risk. J Allergy Clin Immunol 2010; 125: 600-608.

3 Reddel HK, Taylor DR, Bateman ED, et al. An official American Thoracic Society/European Respiratory Society statement: asthma control and exacerbations: standardizing endpoints for clinical asthma trials and clinical practice. Am J Respir Crit Care Med 2009; 180: 59-99.

4 Bousquet J, Mantzouranis E, Cruz AA, et al. Uniform definition of asthma severity, control, and exacerbations: document presented for the World Health Organization Consultation on Severe Asthma. J Allergy Clin Immunol 2010; 126: 926-938.

5 Barrett A, Clark M, Demuro C, et al. Proxy-reported questionnaires for young children with asthma: a structured review. Eur Respir J 2013; 42: 513-526.

6 Humbert M, Holgate S, Boulet LP, et al. Asthma control or severity: that is the question. Allergy 2007; 62: 95-101.

7 Juniper EF, Bousquet J, Abetz L, et al. Identifying "well-controlled" and "not well-controlled" asthma using the Asthma Control Questionnaire. Respir Med 2006; 100: 616-621.

8 Wood PR, Smith B, O'Donnell L, et al. Quantifying asthma symptoms in adults: the Lara Asthma Symptom Scale. J Allergy Clin Immunol 2007; 120: 1368-1372.

9 Lara M, Edelen MO, Eberhart NK, et al. Development and validation of the RAND Asthma Control Measure. Eur Respir J 2014; 44: 1243-1252.

10 Nathan RA, Sorkness CA, Kosinski M, et al. Development of the asthma control test: a survey for assessing asthma control. J Allergy Clin Immunol 2004; 113: 59-65.

11 Marcano Belisario JS, Huckvale K, Greenfield G, et al. Smartphone and tablet self management apps for asthma. Cochrane Database Syst Rev 2013; 11: CD010013. 
12 Wewers ME, Lowe NK. A critical review of visual analogue scales in the measurement of clinical phenomena. Res Nurs Health 1990; 13: 227-236.

13 Global surveillance, prevention and control of chronic respiratory diseases: a comprehensive approach. Geneva, World Health Organization, 2007. Available from: www.who.int/respiratory/publications/global_surveillance/en/

14 Bousquet PJ, Combescure C, Klossek JM, et al. Change in visual analog scale score in a pragmatic randomized cluster trial of allergic rhinitis. J Allergy Clin Immunol 2009; 123: 1349-1354.

15 Gupta D, Aggarwal AN, Subalaxmi MV, et al. Assessing severity of asthma: spirometric correlates with visual analogue scale (VAS). Indian J Chest Dis Allied Sci 2000; 42: 95-100.

16 Flood EM, De Cock E, Mork AC, et al. Evaluating preference weights for the Asthma Symptom Utility Index (ASUI) across countries. Health Qual Life Outcomes 2006; 4: 51.

17 Laforest L, El Hasnaoui A, Pribil C, et al. Asthma patients' perception of their ability to influence disease control and management. Ann Allergy Asthma Immunol 2009; 102: 378-384.

18 Ohta K, Bousquet PJ, Akiyama K, et al. Visual analog scale as a predictor of GINA-defined asthma control. The SACRA study in Japan. J Asthma 2013; 50: 514-521.

19 Bousquet J, Addis A, Adcock I, et al. Integrated care pathways for airway diseases (AIRWAYS-ICPs). Eur Respir J 2014; 44: 304-323. 